Motrivivência Ano XXII, No 34, P. 156-169 Jun./2010

DOI:10.5007/2175-8042.2010n34p156

\title{
PROFESSORES UNIVERSITÁRIOS EM REDE: um jeito hacker de ser ${ }^{1}$
}

Nelson De Luca Pretto²

\begin{abstract}
Resumo
O artigo apresenta quem são e como trabalham os hackers e discute mais especificamente a sua ética e, com isso, aprofunda a perspectiva de colaboração e o papel das tecnologias digitais de informação e comunicação. A partir disso, faz uma reflexão sobre a o papel dos professores universitários na formação dos professores, propondo a criação de redes de comunicação e aprendizagem. Ao final, apresenta uma breve descrição sobre a distribuição das instituições públicas de ensino superior na Bahia e as potencialidades da construção de redes de comunicação e aprendizagem.

Palavras-chaves: Formação de professores; Universidade; Rede; Ética hacker; Colaboração.
\end{abstract}

\begin{abstract}
The article presents whom are and how work the hackers, discusses especially their ethic and with that, goes into the perspective of collaborating and the paper of the digital technologies of communication. From that, makes a reflection about the paper of university professors in the teacher's education, proposing the creation of communication and learning nets. Finally, shows a short description about the distribution of Public High Education Institutions in Bahia and the potentialities of constructing communication and learning nets.

Key-words: Teachers Education; University; Net; Hacker Ethic; Collaboration.
\end{abstract}

1 Texto apresentado no Simpósio "Formação de professores e a cibercultura" e publicado no livro n. 3 do XV ENDIPE (Belo Horizonte, 20 a 23.04.2010); disponível em http://www.fae.ufmg.br/endipe

2 Professor da Faculdade de Educação/Universidade Federal da Bahia; Doutor em Comunicação (USP); Pesquisador do CNPq. Contatos: www.pretto.info; nelson@pretto.info 
Neste texto parto da compreensão sobre quem são e como trabalham os hackers, para discutir mais especificamente a sua ética e, com isso, aprofundar a perspectiva de colaboração e o papel das tecnologias digitais de informação e comunicação, com um especial foco nos processos de partilhamento de arquivos na internet - o peerto-peer ( $2 p)-$, para concluir com uma reflexão sobre o papel dos professores universitários na formação de professores. Nesta última parte, trago uma breve descrição sobre a distribuição das instituições públicas de ensino superior na Bahia e as potencialidades da construção de redes de comunicação e aprendizagem.

\section{Os hackers}

Pensar nos hackers levanos, de uma maneira geral, a associá-los com as pessoas que trabalham com computação. De fato, a expressão foi criada para designar os jovens que atuam com grande envolvimento no campo da programação de computadores. $\mathrm{O}$ trabalho desses jovens - profissionais ou amadores - possui algumas importantes características que geraram para o finlandês Pekka Himanen os princípios da ética hacker, publicado em seu livro $A$ ética dos hackers e o espírito da era da informação, de 2001.

Os hackers podem ser definidos a partir do /argon $\mathrm{File}^{3}$, um espaço na internet onde os envolvidos com a computação definem os principais termos da área, como sendo:

1. Uma pessoa que gosta de aprender os detalhes dos sistemas de programação e ampliar as suas capacidades, em oposição à maioria dos usuários que prefere apenas aprender o mínimo necessário. 2. Alguém que programa entusiasticamente, ou que gosta de programar não apenas de teorizar sobre programação. 3 . Uma pessoa capaz de apreciar o valor hacker. 4. Uma pessoa que é boa e rápida em programação. (...) 5. Um especialista em um determinado programa, ou que frequentemente trabalha com um programa em particular. (JARGON FILE, s/d)

Mas eles também podem ser definidos como " 6 . Um intruso mal-intencionado ou curioso que tenta descobrir informações entrando nos sistemas (JARGON FILE, s/d), o que terminou sendo a definição mais conhecida dos hackers.

Pekka Himanen continua a caracterização dos hackers como sendo aqueles que, além de apaixonados pela programação de computadores,

3 http://www.dourish.com/goodies/jargon.html 
são também apaixonados por tudo o mais que fazem de forma compartilhada. Podemos considerar que, de fato, o hacker pode ser qualquer profissional que atue de forma entusiasmada na sua profissão. Ainda de acordo com o Jargon File, recuperado por Assis Medeiros em sua dissertação de mestrado sobre o tema, "[..] Alguém poderia ser, por exemplo, uma hacker de astronomia. Alguém que busca o desafio intelectual de forma criativa e procura, desta forma, superar as limitações impostas"(MEDEIROS, 2002, p. 38).

Pekka Himanen analisou o trabalho desses profissionais que, em última instância, foram os responsáveis pelo grande avanço da rede internet no mundo e, assim, definiu os princípios que caracterizam a chamada ética hacker, merecendo destaque o fato de eles considerarem o compartilhamento a melhor solução para a resolução dos problemas. Ou seja, para eles, o compartilhamento é a sua crença mais forte. Além disso, tudo - conhecimentos, máquinas e infraestrutura - tem que estar acessível, disponível para todos e de forma descentralizada. Himanen afirma que para ser um hacker é importante gostar daquilo que está fazendo. Mais do que isso, ele destaca que uma das importantes características do trabalho hacker é a paixão. Permitam-me resgatar aqui, entrando de forma quase abrupta no campo educacional, o depoimento da professora Juvany Viana, líder espiritual e professora de escola básica no Recôncavo Baiano, convidada por nós para dar uma aula inaugural de semestre letivo 2001 na Faculdade de Educação da Universidade Federal da Bahia. Perguntada sobre o que para ela é ser professor, ela afirmou de forma categórica: "Ser professor é ser bom amigo, ter uma boa compreensão, saber amar, ter uma frequencia de carinho. (...) é ser compreensivo, é saber amar" (PRETTO; SERPA, 2002, p. 90). Com isso, já deixamos aberto o caminho para a aproximação do trabalho dos hackers com o trabalho dos formadores de professores que será retomado ao longo deste texto.

O outro aspecto da chamada ética hacker é o resgate da dimensão lúdica do seu trabalho de forma a considerar o jogo, o prazer de brincar, como sendo elementos constituidores do jeito hacker de ser. Por último, e não menos importante, é preciso que exista o desejo de explorar e não do simples reproduzir. Resgatar e, principalmente, fortalecer a curiosidade, característica marcante da juventude, é algo que não pode ser esquecido e que precisa estar presente no nosso trabalho docente. Nas palavras de Steven Levy (1994, p. 7), o que os hackers querem "é essencialmente tomar as máquinas 
em suas mãos para melhorar as próprias máquinas e o mundo".

Partindo dessas idéias e pensando na necessária montagem de redes de comunicação e aprendizagem, apresentamos a seguir algumas reflexões no campo da formação de professores.

\section{A cultura da liberdade}

Os princípios da ética hacker anteriormente postos demandam ações tanto em âmbito individual como coletivo e, também, políticas públicas que compreendam e catalisem as ações dos professores com vistas a montagens de redes de comunicação e aprendizagem, especialmente para a formação de professores.

Um dos aspectos a se aprofundar no âmbito das universidades - especialmente as públicas, e esse será exclusivamente o meu foco neste texto - diz respeito à democratização e socialização da produção acadêmica e as possibilidades trazidas para os processos formativos da implantação das redes. Aqui, o tema copyleft é básico e a ele vamos dedicar um espaço. Copie, use, reutilize, remixe toda a produção realizada, e com isso trazemos mais uma vez o tema do compartilhamento. Compartilhamento esse que está associado à ideia de "rossio não rival", uma vez que não estamos mais tratando e trabalhando com bens escassos, e sim com bens imateriais que podem ser partilhados sem perda para as partes. Uma frase atribuída a Bernard Shaw e resgatada por Imre Simon no seu capítulo O Rossio não-rival, do livro Além das Redes de Colaboração (PRETTO; SILVEIRA, 2008), define essa relação entre bem rival e bem não rivais:

Se você tiver uma maça e eu tiver uma maça e nós trocarmos nossas maças então cada um continuará tendo uma maça [é o produto físico maça que está em jogo]. Mas se eu tiver uma ideia e você também e trocarmos nossas idéias cada um terá duas idéias (p. 15).

Portanto, o que preside a discussão sobre a cultura da liberdade é a generosidade, a colaboração, a ética, o compartilhamento, a capacidade de ouvir para pode interagir mas que, lamentavelmente, cada vez mais tem ficado longe da educação.

Necessário se faz, portanto, pensar a educação articulando-a de forma mais intensa com outras áreas do conhecimento, tendo a discussão que articula esse conjunto de áreas sido intensificada nos últimos anos, justamente pelo potencial trazido pela presença das tecnologias digitais de informação 
e comunicação.

Aqui, todo o cuidado é pouco porque o que se observa é que essas tecnologias que possibilitam o trabalho em rede são, muitas vezes, trazidas para a educação como meras ferramentas auxiliares dos processos. Como temos insistido, é fundamental afastar definitivamente a ideia de que a internet e os computadores são meras ferramentas auxiliares do nosso trabalho, pois ao contrário, buscamos compreendê-las enquanto espaços sociais (POSTER, 2001) e como elementos estruturantes dos processos educacionais (PRETTO, 1996).

O exemplo dos aparelhos celulares pode ser ilustrativo de um movimento de apropriação das tecnologias feito pelos usuários, notadamente pela juventude. Os primeiros aparelhos nada mais eram do que simples telefones móveis, que possibilitavam fazer e receber chamadas. Os primeiros movimentos da indústria no sentido de transformá-lo em um aparelho de recebimento de informações ocorrem no final dos anos 90, com os primeiros projetos utilizando os protocolos de aplicações sem fio, desenvolvidos para o acesso à internet através dos telefones móveis. Naquele momento, o objetivo era transformá-los em receptores móveis de informações que incluíam utilidade pública como trânsito, previsão de tempo, cotação de bolsa de valores, entre outros. A ideia nos primeiros momentos era a distribuição de informações jornalísticas em tempo real. Nada diferente, portanto, exceto pela velocidade da transmissão e mobilidade, dos tradicionais meios de comunicação de massa (rádio, jornais, tvs).

O que aconteceu, todavia, tanto pelo movimento da indústria como também pelo movimento da juventude, foi que esta, tão logo percebeu as possibilidades trazidas por esses meios móveis de comunicação, apropriou-se das tecnologias e também a transformou. Os jovens passaram a usar os celulares como meio de expressão, enviando SMS (short message system - sistema de mensagens curtas), colocando fotos no Orkut, Flicker, Myspace ou Facebook, enviando mensagens para o Twitter, Identi.ca e outros microblogs, ou mesmo alimentando os seus próprios blogs pessoais. Esse intensivo uso possibilitou que essa juventude, hoje, interaja com os chamados meios de comunicação de massa pautando, muitas vezes, a própria ação desses meios através do envio de notícias e imagens em tempo real de todos os cantos do planeta.

Isso não está mais sendo feito somente pela juventude, tendo-se que reconhecer o importante papel indutor que ela representa no relacionamento com as tecnologias. 
Isso está sendo feito cotidianamente nos movimentos ativistas em defesa dos direitos humanos, ambientais e de liberdade de expressão. São apenas alguns exemplos o caso do Irã, quando toda a imprensa não conseguia publicar informações mais precisas sobre o que lá acontecia e os jovens começaram a, imediatamente, colocar o Irã no mundo denunciando as eleições e lutando pelas liberdades democráticas; e da mesma forma os recentes casos de Honduras, onde, mais uma vez, as grandes redes de comunicação não conseguiam informações precisas sobre a ocupação da embaixada brasileira pelo deposto presidente Zelaya e os twitteiros imediatamente começaram a mandar notícias e informações para todo o mundo.

Todo esse movimento traz para os mais velhos, e notadamente os professores, um grande desconforto. Desconforto que vai da própria dificuldade de escrever com o dedo polegar nos cada vez mais minúsculos teclados desses aparelhos móveis, até a não compreensão da potencialidade do uso dessas tecnologias digitais. No entanto, tudo isso vem possibilitando a criação e o desenvolvimento de projetos que têm na colaboração aberta o seu elemento constituidor mais forte. $\mathrm{O}$ grande exemplo, repetido em todos os fóruns e textos, é o da enciclopédia livre Wikipedia ${ }^{4}$. Pesquisa publicada na revista Nature mostrou que de uma maneira geral a Wikipedia e a tradicional Enciclopédia Britânica são equivalentes em termos de precisão nos seus verbetes (WEINERGER, 2007, p. 138). O diferencial, contudo, é que a correção de erros encontrados nessas enciclopédias, para a Wikipédia pode se dar em poucos dias.

Esta perspectiva de colaboração na produção de conhecimento é importante para a educação e isso se dá a partir de um movimento de constituição de redes de relacionamento, tecnológicas ou não. Exemplo de uma rede que não necessariamente se estabelece a partir das tecnologias, mas que a usa de forma intensa, é o movimento da Economia Solidária, política pública do governo federal brasileiro desenvolvida pelo Ministério do Trabalho e Emprego através da Secretaria Nacional de Economia Solidária ${ }^{5}$, que vem promovendo a articulação de forma intensa das produções locais por meio das tecnologias, criando um movimento de solidariedade e organização das produções locais que, com isso, conseguem se articular nacionalmente para atingir um

4 http://www.wikipedia.com

5 http://www.mte.gov.br/ecosolidaria/secretaria_nacional.asp 
mercado antes distante. Fortalecese, dessa forma, a produção de bens locais implantando-se uma rede de solidariedade. Esses movimentos em torno das cadeias produtivas locais são suportados por diversos agregadores como, entre outros, o Fórum Brasileiro de Economia Solidária ${ }^{6}$ e o Cirandas, um espaço para que cada empreendimento de economia solidária no Brasil possa ter "um lugar na internet para apresentar a história e o trabalho do seu grupo, ter uma vitrine de seus produtos ou serviços, fazer contatos e utilizar esse endereço virtual inclusive nos seus materiais de divulgação e cartão de visitas" ${ }^{\prime 7}$, além de possibilitar uma maior articulação para compras e vendas de produtos e a articulação política em torno do próprio movimento solidário. Este vem se constituindo em um movimento ativista totalmente sintonizado com os princípios do movimento hacker. Um movimento de pegar as coisas, pôr a mão na massa e, simplesmente, fazer a diferença. Em ambos, a lógica do compartilhamento está presente de forma intensa.

Podemos também pensar em outros movimentos no campo da cultura, os movimentos de troca de arquivos através da internet, conhecido como peer-to-peer, que significa troca entre pares, mas que pode significar, numa tradução mais coloquial e interessante, de troca entre amigos, entre parceiros, possibilitando a dinâmica de produção colaborativa com uma intensificação da produção de conhecimentos e culturas.

Um exemplo significativo nesse campo é a música. O que se tem visto é a produção de músicas que circulam livremente na rede. São artistas que se articulam em torno de cooperativas ou em suas próprias casas, com computadores usando software livre e criando, produzindo, gravando e distribuindo suas músicas em CDs ou pela internet, já provocando a própria indústria fonográfica que luta de forma intensa para bloquear esse movimento. São exemplos no Brasil o movimento Música Para Baixar ${ }^{8}$ e internacionalmente o site Jamendo 9 . São muitos os outros exemplos e práticas ativistas que poderíamos descrever e analisar aqui, mas não o faremos por questão de espaço. É importante, porém, destacar o movimento em torno da Cultura Digital no Brasil que vem

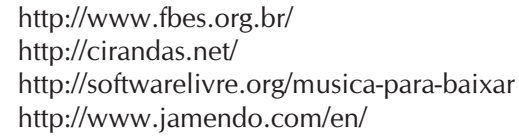


sendo articulado pelo Ministério da Cultura com diversos ativistas e organizações que atuam na área. O Fórum de Cultura Digital ${ }^{10}$, que acontece na internet, vem discutindo vários aspectos dessa temática, contribuindo para a implantação de políticas públicas catalisadoras dessas ações culturais, com forte reflexo no campo da educação.

Esse crescimento da cultura do partilhamento está também presente nas universidades. Crescem dois grandes movimentos que são importantes para o estabelecimento das redes a que estamos nos referindo. Um desses movimentos é a adoção por diversas instituições ligadas à educação, ciência e cultura das revistas abertas, livres para o acesso de todos. Esse movimento no Brasil vem sendo liderado pelo Instituto Brasileiro de Informação em Ciência e Tecnologia (IBICT), vinculado ao Ministério da Ciência e Tecnologia (MCT), que adotou a política de arquivos abertos (open archives), associando-se ao Projeto de Conhecimento Público (Public Knowledge Project). O PKP desenvolveu um sistema livre para administrar publicações e indexações de revistas acadêmicas, o Open Journal System, que foi traduzido para o português pelo IBICT e implantado em diversas instituições. O crescimento do sistema no Brasil demonstra um ainda tímido, mas promissor, avanço em direção à democratização do conhecimento acadêmico produzido no país: em 2004, quando o sistema foi disponibilizado, eram 22 revistas. Em 2008 eram 315 em acesso aberto, ${ }^{12}$ criando, dessa forma, novas possibilidades para a ampliação do acesso para toda a população dos países falantes da língua portuguesa da produção científica nacional e internacional. Com isso viabiliza-se, cada vez mais, que os resultados das pesquisas, principalmente as financiadas com recursos públicos, possam ser oferecidos sem custos à sociedade que, em última instância, já pagou por eles.

Uma segunda vertente é a produção de recursos educacionais abertos, licenciados em formatos livres que possibilitam o seu intenso uso nas universidades para os seus processos formativos. Esse é um tema candente na pesquisa educacional em todo o mundo, mas não será objeto de nossa análise neste momento.

O crescimento da cultura do compartilhamento associado com os movimentos que mencionamos

10 http://culturadigital.br/

11 http://seer.ibict.br/index.php?option =com_content\&task = view\&id = 395\&ltemid = 120 
anteriormente traz para o debate outro importante tema, com forte vínculo com a educação: o software livre ou software de código aberto. Uma vez que o software livre é produzido essencialmente de maneira colaborativa, sua relação com a educação é quase que direta quando consideramos que não existe possibilidade de implantação de processos formativos, especialmente se nos referimos à formação de professores, se não pensarmos no coletivo, em colaboração e, portanto, em rede. Afinal, não deveriam ser esses os princípios fundamentais da educação? Lamentavelmente não o são. No entanto, podemos pensar no resgate destes princípios a partir de uma apropriação das tecnologias digitais com um fortalecimento da rede que, com elas, pode se estabelecer.

\section{As redes}

A montagem de uma redede formação de professores envolvendo as instituições públicas de ensino superior do país é uma condição básica para que possamos superar o grande desafio da formação de professores. Dados do relatório "Educação para Todos 2006 - Professores e Educação de Qualidade", da Organização das Nações Unidas para Educação, Ciência e Cultura, mostram que o Brasil é, na América Latina, um dos países com menor grau de formação de seus docentes. Os dados do estudo indicaram que a maioria dos professores brasileiros de $1^{\mathrm{a}} \mathrm{a}$ $4^{\mathrm{a}}$ série $(92 \%)$ tem apenas o ensino médio com mais um ano ou dois de formação específica (ESTADÃO, 2006). Segundo o referido estudo, até o ano de 2015 o Brasil precisará de mais 396 mil professores para manter o atendimento nas escolas de ensino básico. Mesmo com todos os investimentos que o governo vem fazendo na ampliação da rede de formação de professores através da modalidade à distância, os números apontam para a necessidade de uma verdadeira revolução nas ações de formação de professores se pensamos em sair desse fosso.

Tomando como caso de estudo a distribuição das Instituições Públicas de Ensino Superior no Estado da Bahia no ano de 2006, percebemos o papel que essas universidades públicas poderiam representar no esforço da formação dos licenciados para as diversas áreas no Estado. Essas ações, articuladas com o mesmo espírito hacker que anteriormente descrevemos, necessitariam ser desenhadas pensando para além dos muros de cada universidade e de cada campus universitário. Mais do que isso, a articulação com as culturas locais passaria ser a mola mestra de todas as 
ações formativas se pensarmos em uma formação de educadores comprometidos com as necessárias transformações da sociedade brasileira, que vive em profundas desigualdades.

Pensamos cultura como força motriz, compreendida, ao mesmo tempo, como elemento galvanizador e direcionador do desenvolvimento científico e tecnológico e como fonte inspiradora de um sistema educacional integrado desde a pré-escola, sendo esse o nosso propósito teórico e político. Uma cultura cujos pilares são a língua, a geografia, a fauna, a flora, e que se firma sobretudo através da educação e no desenvolvimento das artes, da ciência e da tecnologia. Uma cultura assim consolidada tem diálogo histórico e soberano com culturas de outros países e, mais recentemente, com a chamada cultura global que insiste em, justamente, destruir as culturas locais pela sua força homogeneizante. Imaginamos ser importante um outro olhar sobre as nossas universidades, voltando-se para o passado para resgatá-lo de forma radical, sem saudosismo, ou apesar dele, de tal forma a recuperar a perspectiva pública, aberta a todos os segmentos da sociedade e socialmente referenciada, que caracteriza o ethosuniversitário.

Perdemos muito de tudo isso porque perdemos muito desta perspectiva de vida e, também, de universidade. A universidade está sem capacidade de contemplar! Viraram máquinas ou peças de um sistema que necessita produzir de forma quase alucinada. Universidade shopping centerou, como um supermercado onde se entra, pega-se um produto - uma aula?! - e paga-se na saída. O violento processo de privatização do ensino superior nas últimas décadas tem nos trazido esta lamentável experiência de forma contundente. Essa lógica tem levado as universidades a olharem muito mais para o mercado do que para a formação geral dos cidadãos, não lhes possibilitando, inclusive, estabelecer uma crítica ao próprio mercado. O responsável pelas universidades parisienses, Maurice Quénet, foi categórico ao afirmar em uma entrevista que o papel de uma universidade não deve ser o de preparar para o mercado de trabalho, mas o de dar uma formação geral aos jovens (FOLHA, 2006).

Perdeu-se o espaço para os embates políticos, acadêmicos e ideológicos nas universidades. A discussão política esvaziou-se porque tudo tem que ser rápido. Na prática, aderimos à lógica da Organização Mundial do Comércio e de todas as demais políticas planetárias: viramos commodities. Impera a lógica do ranking e, com isso, estimula-se a 
ideia de sermos os primeiros, os melhores, os mais rápidos.

Como o dinheiro público

para o financiamento das universidades públicas continua escasso mesmo com todos os investimentos realizados pelo governo federal nos últimos anos, as instituições e os professores correm atrás de financiamento com uma busca alucinada pela captação de recursos, impondo uma lógica de competição entre as próprias universidades. No ano de 2006 fizemos um levantamento do número de universidades públicas na Bahia e da localização de todos os seus campi universitários espalhados pelo Estado, principalmente por conta da Universidade do Estado da Bahia (Uneb), uma universidade criada de forma multicampi.

Com a colaboração da Companhia de Desenvolvimento Urbano do Estado da Bahia (CONDER) plotaram-se todos esses campi no mapa do Estado, e a partir deles traçou-se um círculo com um raio máximo de $100 \mathrm{~km}$ para podermos visualizar a amplitude da cobertura das IES públicas baianas no Estado.

Foram as seguintes as unidades consideradas no ano de 2006: Universidade Federal da Bahia (Salvador, Barreiras e Vitória da Conquista); Universidade Federal do Recôncavo Baiano (Campus de Cruz das Almas, Campus de Santo Antônio de Jesus, Campus de Cachoeira e Campus de Amargosa); Universidade do Vale do São Francisco (Campus Juazeiro - BA); Universidade do Estado da Bahia (Salvador, Alagoinhas, Juazeiro, Jacobina, Santo Antonio de Jesus, Caetité, Senhor do Bonfim, Paulo Afonso, Barreiras, Teixeira de Freitas, Serrinha, Guanambi, Itaberaba, Conceição do Coité, Valença, Irecê, Bom Jesus da Lapa, Eunápolis, Camaçari, Brumado, Ipiaú, Euclides da Cunha, Seabra e Xique-Xique); Universidade Estadual de Feira de Santana (Feira de Santana, Lençóis e Santo Amaro); Universidade Estadual de Santa Cruz; Universidade Estadual do Sudoeste da Bahia (Vitória da Conquista, Jequié e Itapetinga); CEFET-BA (Barreiras, Eunápolis, Vitória da Conquista, Valença, Salvador, Simões Filho, Santo Amaro, Porto Seguro, Camaçari) e as Escolas Agrotécnicas Federais na Bahia (Catu, Guanambi, Santa Inês e Senhor do Bonfim).

O gráfico a seguir mostra a cobertura do sistema universitário baiano em termos geográficos. 


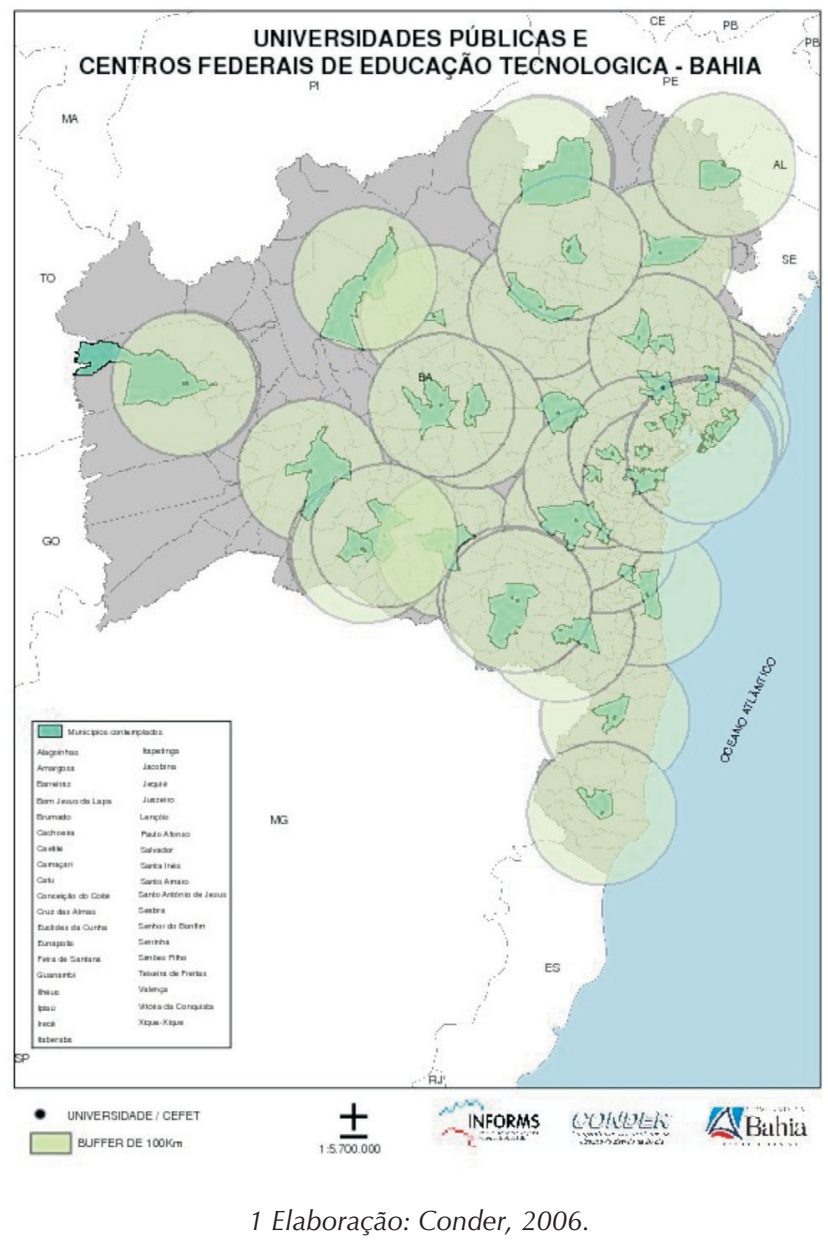

Observa-se claramente que se pensarmos em termos estaduais, praticamente todo o Estado está coberto por pelo menos um campus de uma universidade pública, numa distância máxima de $100 \mathrm{~km}$. Tanto nas sedes como nos campi universitários encontramos as unidades voltadas para a educa- ção, sejam as próprias Faculdades ou Centros ou então os departamentos de Educação. Elas constituem-se, portanto, num potencial incomensurável de transformação já que ali estão os profissionais que pensam a educação em nosso país. Não resta a menor dúvida que elas sofrem de todas as conhecidas mazelas do 
sistema público de ensino superior. No entanto, no conjunto das FACED, encontramos experiências muito ricas que podem ser estimuladas e articuladas se implantamos redes de comunicação e formação conectando todas essas experiências e expertise. Esse é seguramente um enorme potencial e poderia incluir o fortalecimento de redes de bibliotecas, de produção de materiais culturais (e educacionais), de um sistema de comunicação pública, entre tantos outros. O estabelecimento de uma rede horizontal é de fundamental importância para que seja possível adotar uma outra perspectiva para as universidades e o sistema educacional. São novas possibilidades que se instalam e que modificam os tradicionais vetores de desenvolvimento que sempre apontam da capital para o interior, como se o interior fosse constituído de espaços virgens que as redes iriam resgatar e tirar da sua pureza e da sua ingenuidade. Dessa forma, pensar a conexão de um campus universitário pode e deve corresponder à conexão da região onde a universidade está inserida na própria rede. E ao conectar mais uma região à rede, ela própria se transforma, mas também a rede sofre transformação com a sua presença. Como afirma Leila Dias (1995, p. 148), pesquisadora da Universidade Federal de Santa Catarina, "as redes não vêm arrancar territórios 'virgens' de sua letargia, mas se instalam sobre uma realidade complexa que elas vão certamente transformar, mas onde elas vão igualmente receber a marca".

Dentro das regiões, novamente a rede se estabelece, articulando as universidades com as demais unidades do sistema público de ensino. Implanta-se potencialmente um processo contínuo e permanente de troca, de formação continuada em serviço com a rede desenvolvendo programas de formação em rede, para as diversas áreas do conhecimento, onde a produção de conhecimentos e culturas seja priorizada. Para tal, é importante salientar que se torna necessário o envolvimento da escola como um todo e não o professor isoladamente, enquanto indivíduo. Obviamente, pensamos que toda essa produção precisa estar licenciada de forma livre, possibilitando que, na rede, novos produtos derivados dos produtos originais possam surgir. Essa produção inserida nas redes de comunicação e aprendizagem, através da internet, ganha o mundo e com ele interage. Assim, os princípios da ética hacker passam a fazer parte do cotidiano dos processos de formação dos professores.

Nesse momento esse professor hacker vai ampliar a sua rede colaborativa e é exatamente isso 
que a educação demanda. Nós não podemos parar nossa formação, ela precisa ser contínua, permanente; é isso que fortalece nossas escolas além de equipamentos e outras condições de trabalho adequadas.

\section{Referências}

CUNHA, Luis Antonio. universidade reformada. Rio de Janeiro: Francisco Alves, 1988.

DIAS, Leila Christina. Redes: emergência e organização. In: CASTRO, Iná Elias; GOMES, Paulo Cesar da Costa; CORRÊA, Roberto Lobato (Orgs.). Geografia: conceitos e temas. Rio de Janeiro: Bertrand Brasil, 1995. p. 141-162.

Folha de S. Paulo. Universidade não deve focar mercado, afirma responsável pela Sorbonne. Caderno Cotidiano, edição de $1 \% / 5 / 2006$.
JARGON FILE, The Original Hacker's Dictionary, http://www.dourish. com/goodies/jargon.html, acesso em 18.10.2009.

LEVY, Steven. Hackers: heroes of the computer revolution. New York, Penguin Books, 1994.

MEDEIROS, Assis. Hackers: entre a ética e a criminalização. Visual Books, 2002, 182.

O Estado de S. Paulo. Brasil precisará de mais 396 mil professores até 2015 , de 28/4/2006, acesso 22.2.2010.

POSTER, Mark. What's the matter with the Internet. Minneapolis: University of Minnesota Press, 2001.

WEINBERGER, David. Everything is miscellaneous: The power of the new digital disorder, Macmillan, 2007.

Recebido: julho/2010. Aprovado: outubro/2010. 